\title{
La naturaleza del procedimiento de protección al consumidor del Indecopi y la oportunidad de desistimiento en aquel
}

\author{
Rodrigo Peláez Ypanaqué
}

\section{Introducción}

La doctrina clásica suele clasificar el procedimiento administrativo en procedimiento general y procedimientos especiales. Estos últimos comprenden el procedimiento trilateral y el procedimiento sancionador.

Un procedimiento administrativo trilateral puro, regulado en los artículos 219 al 228 de la Ley 27444, Ley del Procedimiento Administrativo General (en adelante, LPAG), es aquel en el cual la Administración participa decidiendo un conflicto entre administrados, por lo que carece de la condición de parte al ser totalmente ajena a la relación jurídica discutida.

Un procedimiento administrativo sancionador, regulado en los artículos 229 al 237 de la LPAG, es aquel dirigido a regular las conductas que infrinjan las normas de derecho administrativo dentro de un Estado social y democrático de derecho y que no requieran ser sancionadas penalmente, siendo una manifestación del ejercicio del ius puniendi del Estado.

Dada su finalidad sancionadora, este procedimiento es iniciado de oficio, debido a que la actividad que pone en ejercicio la Administración (sancionadora) y la consecuencia que surge tras ella (la sanción) corresponden a atribuciones que solamente esta puede ejercer.

Por tanto, los procedimientos administrativos califican como trilaterales o como sancionadores, dependiendo de las características que se presenten en cada uno de ellos. 
Sin embargo, en lo referente a la naturaleza del procedimiento de protección al consumidor seguido ante el Indecopi, la doctrina no es pacífica al momento de calificarlo como un procedimiento administrativo sancionador o como uno trilateral.

\section{La naturaleza de los procedimientos de protección al consumidor}

Para algunos autores, los procedimientos de protección al consumidor que se tramitan ante el Indecopi califican como procedimientos sancionadores y para otros como procedimientos trilaterales.

\subsection{La naturaleza sancionadora de los procedimientos de protección al consumidor}

El Estado mantiene con los consumidores o usuarios un "deber especial de protección" que se encuentra constitucionalizado en nuestro ordenamiento jurídico ${ }^{1}$. Una de las formas a través de las cuales el Estado ha considerado que debe ejercer esta tutela es mediante la sanción de aquellas conductas que desconozcan o resulten lesivas de los derechos reconocidos a los consumidores.

La incorporación de mecanismos de derecho público responde a una nueva visión de Estado acorde con el modelo económico, según la cual una política de protección al consumidor trasciende la solución de los problemas de un consumidor en el marco de su relación individual con el proveedor. La relación de consumo, inicialmente concebida como una relación casi interindividual entre el productor y/o vendedor y el adquirente y/o consumidor, para la cual bastaba el tratamiento a nivel de derecho privado, ha evolucionado de tal manera que requiere en determinadas situaciones nuevos tratamientos jurídicos que vayan más allá de la esfera privada, precisamente por el sobredimensionamiento de los mercados y las operaciones que se dan dentro de ellos, haciendo necesario su tratamiento por las normas de derecho público estatal: constitucionales, administrativas, etc. (Corrientes, 1994, p. 8).

1 Constitución Política del Perú.- Artículo 65.- El Estado defiende el interés de los consumidores y usuarios. Para tal efecto garantiza el derecho a la información sobre los bienes y servicios que se encuentran a su disposición en el mercado. Asimismo, vela, en particular, por la salud y seguridad de la población. 
En ese sentido, un sector de la doctrina sostiene que los procedimientos de protección al consumidor poseen una naturaleza sancionadora y señala que los procedimientos sancionadores de protección al consumidor son el mecanismo lógico formal diseñado por el legislador para hacer efectiva la acción de interés público que el Estado ha confiado a las administraciones públicas en el cumplimiento de sus funciones, entre las cuales se encuentra la protección al consumidor.

El procedimiento sancionador administrativo es el instrumento para canalizar la acción punitiva del Estado frente al incumplimiento de las obligaciones establecidas para los proveedores de bienes o servicios en el Código de Consumo, y también para el control que sobre estos es exigible en cuanto al respeto de los derechos de los consumidores, conforme al mandato constitucional establecido en el artículo 65 de nuestra Constitución Política y que implica un deber especial de protección de parte del Estado a los derechos de los consumidores.

En este sentido, el artículo 107 del Código de Consumo señala en forma expresa que, independientemente de la forma de inicio del procedimiento, este es un procedimiento sancionador.

El procedimiento sancionador administrativo en materia de protección al consumidor puede ser iniciado de oficio o de parte, ya sea por iniciativa de la autoridad, por denuncia del consumidor afectado, de aquel que pudiera verse potencialmente afectado o por iniciativa de una asociación de consumidores.

Tratándose de un procedimiento sancionador, e independientemente de que sea una acción de oficio o una denuncia de parte, el procedimiento sancionador administrativo únicamente se inicia de oficio, es decir, con la acción pública que expresa la imputación de cargos, conforme se desprende del numeral 3 del artículo 234 de la LPAG.

Para este sector doctrinario, por medio de la denuncia el administrado pone en conocimiento del órgano administrativo la existencia de un determinado hecho que pudiera constituir infracción administrativa. Ante ello, la Administración tiene el deber de iniciar un procedimiento como consecuencia de la obligatoriedad de la acción punitiva del Estado.

En este escenario, la acción del particular, es decir, de un consumidor en la iniciación del procedimiento sancionador, y el hecho de que pueda canalizar una pretensión de resarcimiento particular, no menoscaban ni restan al hecho de que dicha intervención particular es también una forma en que la autoridad toma noticia directa de un acto contrario al 
cumplimiento de la ley, y que por tratarse de una infracción que viola o desconoce el mandato legal que la Administración tiene confiado cautelar en su cumplimiento, no le pertenece ya al denunciante, sino que más bien forma parte del deber ineludible de intervención al que está obligada la autoridad, de conformidad con lo dispuesto en el artículo 63, inciso 3, de la LPAG.

Por esta razón, el consumidor, una vez que se ha sancionado al infractor, únicamente tiene dentro de su dominio de disposición la expectativa por el resarcimiento, mas no sobre la actividad punitiva del Estado respecto a la infracción.

En el mismo sentido, el desistimiento únicamente puede producirse antes de la existencia de un pronunciamiento de la autoridad, pues cuando la autoridad se ha pronunciado y ha impuesto una sanción, esta le pertenece al Estado y no puede dejarse sin efecto por el pedido de un particular.

Por tanto, la acción de desistimiento del consumidor únicamente podría alcanzar los derechos subjetivos que accesoriamente a la sanción puedan derivarse del procedimiento (medidas correctivas, por ejemplo).

No es posible que el consumidor pueda desistirse de lo que no le pertenece: el conocimiento de un hecho contrario al marco legal, que la autoridad está obligada a sancionar.

\subsection{La naturaleza trilateral de los procedimientos de protección al consumidor}

Para otro sector de la doctrina, estos procedimientos tienen una naturaleza trilateral, sin que la naturaleza se vea afectada por la capacidad sancionadora atribuida al órgano administrativo.

En ese sentido, Juan Espinoza Espinoza, en su artículo "Circulación de los modelos jurídicos de la responsabilidad civil en la tutela administrativa de los derechos del consumidor", ha señalado:

[...] en el procedimiento administrativo de tutela del consumidor, este no solo obtiene una medida correctiva (situación que lo calificaría como trilateral), sino también el Indecopi puede imponer una multa al proveedor, lo cual también haría que este procedimiento sea, a la vez, sancionador [...].

No obstante ello, una de las manifestaciones del proceso trilateral es la de dar espacio para la aplicación de sanciones al administrado 
infractor. Por tal motivo, no deberían ser acogidas aquellas interpretaciones que puedan crear una suerte de (innecesario) procedimiento trilateral - sancionador [...] (Espinoza, 2010, p. 304).

Asimismo, Christian Guzmán Napurí, en su obra Tratado de la Administración Pública y del procedimiento administrativo, considera que tienen una naturaleza trilateral:

El procedimiento trilateral se inicia mediante la presentación de una reclamación o de oficio. La reclamación es el escrito a través del cual el interesado activa el procedimiento trilateral [...].

Ahora bien, es posible la iniciación de procedimientos trilaterales, cuando quien lo inicia es la propia administración. Sin embargo, resultan ser muy raros los procedimientos trilaterales iniciados de oficio. [...]

Ahora bien, la parte que inicia el procedimiento con la presentación de una reclamación se denomina reclamante y cualquiera de los emplazados será designado como reclamado [...]. Es necesario señalar que en el ámbito de los procedimientos seguidos ante el Indecopi se hace referencia a denunciante y denunciado cuando en puridad dichos procedimientos, en su mayoría, son de naturaleza trilateral y no sancionadora, como por ejemplo los procedimientos seguidos ante la Comisión de Protección al Consumidor (Guzmán, 2011, p. 533).

\subsection{La naturaleza mixta de los procedimientos en materia de protec- ción al consumidor}

Otro sector de la doctrina, en el que destaca Hugo Gómez Apac, considera que los procedimientos de protección al consumidor seguidos ante el Indecopi, iniciados por una denuncia, tienen una naturaleza mixta "trilateral-sancionadora", en la cual hay dos relaciones jurídicas: una bilateral de carácter sancionador, donde prima el interés público, y otra trilateral, que alberga los intereses privados, contrapuestos entre el denunciante y el denunciado (Gómez, 2011, p. 29).

Esta postura es acogida por Juan Carlos Morón Urbina, en el informe emitido con fecha 9 de febrero de 2012 a solicitud del Interbank, a raíz de la Resolución 271-2011/INDECOPI - PIU, de 28 de diciembre de 2011. En efecto, en el referido informe se indica que el procedimiento administrativo en materia de protección al consumidor posee una naturaleza mixta "que tiene aspectos que le otorgan un carácter trilateral sin 
que ello perjudique su finalidad sancionadora, a pesar que la LPAG [...] no abarque, específicamente, un procedimiento de esta naturaleza...".

En opinión del jurista Morón Urbina, entender que el procedimiento sancionador en materia de protección al consumidor ante el Indecopi es puramente sancionador no se desprende de sus características, ya que no solo la normativa aplicable acepta su naturaleza particular, como se señala en el artículo 4, numeral 3, de la Directiva 004-2010/DIR-COD-INDECOPI, sino que mantiene algunos de los rasgos particulares del procedimiento trilateral, como la forma de inicio (la cual, a pesar de denominarse de oficio, se originó debido a una denuncia por parte de un consumidor), así como las formas de participación (como la interposición de recursos, que solo quien es parte del procedimiento puede ejercitar) e incluso la potestad de darle término con ciertos mecanismos especiales como el desistimiento o la conciliación.

A mi parecer, esta tesis intermedia es la que describe mejor la naturaleza especial del procedimiento administrativo de protección al consumidor que se sigue ante el Indecopi, pues nos encontramos frente a un procedimiento sancionador que cuenta con ciertos rasgos de un procedimiento trilateral.

Así lo reconoce la Directiva 004-2010/DIR-COD-INDECOPI, Reglas complementarias aplicables al procedimiento sumarísimo en materia de protección al consumidor, en su numeral 4.3.1, que señala: "El procedimiento sumarísimo se inicia de oficio, por denuncia de parte, lo que le otorga una condición trilateral que no altera la naturaleza sancionadora de dicho procedimiento".

La directiva es clara y precisa en la descripción de la naturaleza mixta (sancionadora-trilateral) del procedimiento administrativo en materia de protección al consumidor, por lo que despeja cualquier opción interpretativa distinta sobre su naturaleza. Aun cuando la directiva se refiere al procedimiento sumarísimo, el criterio es plenamente trasladable al procedimiento ordinario por denuncia del consumidor, debido a que, en su esencia, se trata de procedimientos similares.

Podemos concluir, entonces, que si bien en los procedimientos administrativos en materia de protección al consumidor -iniciados por denuncia de parte - se encuentra presente el ejercicio de la potestad sancionadora de la Administración con el propósito de cautelar el interés público involucrado en la defensa de los consumidores, también en ellos 
se discuten derechos subjetivos e intereses legítimos de índole particular, por lo que debe reconocérseles además su naturaleza trilateral.

\subsection{La oportunidad de desistimiento en los procesos de protección al consumidor}

El componente trilateral de los procedimientos justifica la evaluación de los presupuestos de admisibilidad y procedencia de la denuncia, la culminación del procedimiento por conciliación o transacción extrajudicial, la posibilidad del Indecopi de ordenar medidas correctivas reparadoras y, eventualmente, la condena al pago de costas y costos (Gómez, 2011, p. 42). Esta particularidad del procedimiento administrativo atenúa las exigencias propias de un procedimiento sancionador puro, haciendo posible la aplicación de la figura del desistimiento.

El artículo 186 de la LPAG establece que la conciliación, la transacción y el desistimiento son formas de conclusión del procedimiento administrativo. Así también lo reconoce el Código de Consumo, que establece en su artículo 147 que los consumidores pueden conciliar la controversia surgida con el proveedor con anterioridad e incluso durante la tramitación de los procedimientos administrativos por infracción a las disposiciones de protección al consumidor.

El único límite impuesto al desistimiento para su aceptación es que otros terceros interesados en el procedimiento insten por su continuación, luego de que son notificados del desistimiento o de que la autoridad de oficio verifique que tal aceptación pueda afectar intereses de terceros o el interés general. Así lo establecen los numerales 189.6 y 189.7 del artículo 189 de la LPAG.

Si no se ha dado una afectación al interés general o al interés de terceros y no existen terceros interesados en que el procedimiento continúe, corresponde que la autoridad administrativa acepte el desistimiento de plano y declare la conclusión y el archivo definitivo del procedimiento, según lo dispuesto en el numeral 189.6 del artículo 189 de la LPAG.

No cabe una interpretación en contrario, pues ella haría más improbable que el proveedor y el consumidor concreto en conflicto logren un entendimiento a satisfacción de ambas partes, situación que iría en contra de la autocomposición de los conflictos de consumo, que es uno de los principios que inspiran las normas de protección al consumidor y elevado a nivel de política pública (artículo VI, numeral 6, del título preliminar del Código de Consumo). 
Respecto a la oportunidad para el desistimiento, el inciso 5 del artículo 189 de la LPAG establece que se podrá realizar en cualquier momento antes de que se notifique la resolución final en la instancia. La palabra instancia es definida como "cada conjunto de actuaciones practicadas, tanto en la jurisdicción civil como en la criminal, las cuales comprenden hasta la sentencia definitiva" (Cabanellas, 1989, p. 399). En ese sentido,

[...] se llama primera instancia el ejercicio de la acción ante el primer juez que debe conocer del asunto; segunda instancia, el ejercicio de la misma acción ante el juez o tribunal de apelación, con el objeto de que reforme la sentencia del primer juez; y tercera instancia, a la revisión del proceso o causa ante el tribunal superior, según la jurisdicción (Cabanellas, 1989, p. 399).

Dentro del procedimiento administrativo existen dos instancias, por lo que el desistimiento se podrá dar antes de la resolución final de la primera o la segunda instancia. Entender que el desistimiento solo cabe en primera instancia implicaría atentar contra una de las reglas de interpretación más importantes del derecho: distinguir donde la ley no distingue ("ubi lex non distinguit, nec nos distinguere debemus").

La potestad sancionadora de la Administración Pública puede reforzar la protección de los derechos de los consumidores. Pero si un consumidor comprende libremente que su derecho no se encuentra afectado, o habiéndolo estado, el denunciante ha conseguido la satisfacción de su pretensión en paralelo al procedimiento, pues lo más recomendable es que la participación del Estado deba concluir en ese preciso momento, ya que el mejor protector de sus intereses es el propio consumidor.

\section{Conclusión}

De los argumentos expuestos se puede concluir que el procedimiento de protección al consumidor se encuentra normado de manera particular.

En virtud de ello, no se puede afirmar que nos encontramos frente a un procedimiento administrativo en puridad; este procedimiento tiene una naturaleza particular que mezcla caracteres trilaterales y sancionadores.

Por este motivo, como característica tomada del procedimiento trilateral, el administrado denunciante tiene calidad de parte dentro del procedimiento y le puede dar inicio con su denuncia, interponer recursos impugnativos y darle fin a través de su desistimiento. 
El desistimiento puede darse tanto en primera como en segunda instancia, pues no se puede distinguir donde la ley no lo hace. Por tanto, el único límite para que no proceda el desistimiento es que existan intereses de terceros afectados o una afectación al interés general.

La autoridad administrativa debe, en el caso de que solo se haya afectado un interés particular, aceptar de plano el desistimiento y declarar la conclusión del procedimiento, en concordancia con el carácter pro conciliador recogido en las disposiciones del Código de Consumo, que ha sido elevado a política pública por el propio Indecopi.

\section{Referencias}

Cabanellas de Torres, G. (1989). Diccionario jurídico elemental. Buenos Aires: Heliasta.

Corrientes Córdova, J. A. (1994). La protección de los consumidores en Europa Comunitaria: De los tratados fundacionales al de la Unión Europea (Maastricht). En Estudios sobre el derecho de consumo. (2. ${ }^{\mathrm{a}}$ ed.). Bilbao: Iberdrola.

Espinoza Espinoza, J. (2010). Circulación de los modelos jurídicos de la responsabilidad civil en la tutela administrativa de los derechos del consumidor. Actualidad Jurídica, 197. Lima: Gaceta Jurídica.

Gómez Apac, H. (2011). El procedimiento trilateral: ¿cuasijurisdiccional? Revista de Derecho Administrativo, 10. Derecho de la Competencia. Lima: Círculo de Derecho Administrativo.

Guzmán Napurí, C. (2011). Tratado de la Administración Pública y del procedimiento administrativo. Lima: Caballero Bustamante. 
